\title{
The methodology of lymphatic anatomy studies in a cadaver model: an overview
}

\author{
Hiroo Suami ${ }^{1}$, Akira Shinaoka ${ }^{2}$ \\ ${ }^{1}$ Australian Lymphoedema Education, Research and Treatment Program, Faculty of Medicine and Health Sciences, Macquarie University, \\ Sydney, NSW 2109, Australia. \\ ${ }^{2}$ Department of Human Morphology, Okayama University Graduate School of Medicine, Dentistry, and Pharmaceutical Science, Okayama \\ 700-8558, Japan.
}

Correspondence to: Prof. Hiroo Suami, Faculty of Medicine and Health Sciences, Macquarie University, Level 1, 75 Talavera Rd, Sydney, NSW 2109, Australia. E-mail: hiroo.suami@mq.edu.au

How to cite this article: Suami $\mathrm{H}$, Shinaoka A. The methodology of lymphatic anatomy studies in a cadaver model: an overview. Plast Aesthet Res 2019;6:33. http://dx.doi.org/10.20517/2347-9264.2019.46

Received: 28 Oct 2019 First Decision: 20 Nov 2019 Revised: 27 Nov 2019 Accepted: 17 Dec 2019 Published: 26 Dec 2019

Science Editor: Xiao Long Copy Editor: Jing-Wen Zhang Production Editor: Tian Zhang

\begin{abstract}
The lymphatic system is the area least investigated in the field of anatomical science. The major reason for this is the technical difficulty in identifying the lymphatics in the surrounding tissue in post-mortem specimens. As a result, the medical illustration masterpieces crafted by pioneer anatomists on the basis of cadaver dissections remain a vital component of current anatomical textbooks. Several innovative techniques were developed in the past to allow anatomists to distinguish the transparent lymphatic structures from their surroundings and enable thorough investigation of the lymphatic system in a cadaver model. This paper focuses on these techniques, including the current technique developed by the authors themselves.
\end{abstract}

Keywords: Anatomy, lymphatic system, cadaver, mercury, indocyanine green

\section{INTRODUCTION}

Since lymphanagiography was introduced by Kinmonth ${ }^{[1]}$ in the 1950 s, several other imaging techniques have been developed to provide imaging of the lymphatic system in the clinical setting. Lymphoscintigraphy ${ }^{[2,3]}$ is the current gold standard procedure, but indocyanine green (ICG) lymphography ${ }^{[4-6]}$, magnetic resonance lymphography ${ }^{[7,8]}$, and single-photon emission computed





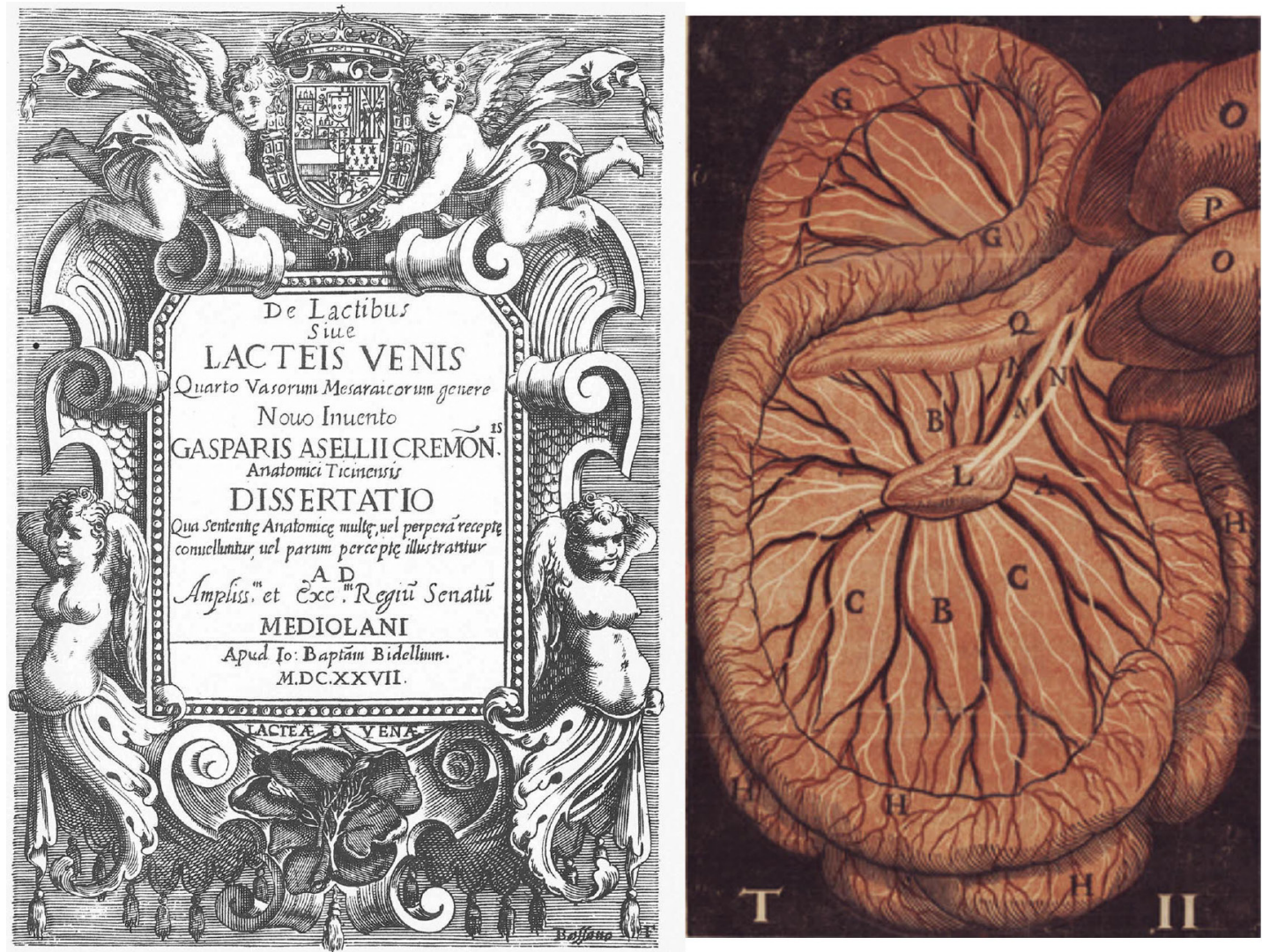

Figure 1. Aselli's ${ }^{[10]}$ publication in 1627. This image shows white lacteal cords in the dog mesentery (right)

tomography (SPECT)/CT ${ }^{[9]}$ are emerging imaging techniques to visualise the lymphatics. The tracers used for these examinations vary according to the procedure and are carried spontaneously via the lymphatic system after being injected into the skin or subcutaneous tissue. Understanding the precise anatomy of the lymphatic system is fundamental for providing a normal control view of the particular body region being examined that in turn enables doctors and researchers to identify changes in patients.

Despite the range of clinical imaging examination techniques, studies of lymphatic anatomy are very limited. The spontaneous transit of lymph fluid terminates in post-mortem specimens and valvular structures inside the lymphatic vessel are located at intervals of a few millimetres. These characteristics mean that retrograde injection from the proximal to the distal is not possible, so injections must be done from distal to proximal. In addition, the lymphatic vessels are transparent and lymph fluid is colourless as it contains no red blood cells, thus it is difficult for anatomists to distinguish lymphatic structure from the surrounding soft tissue. However, pioneer anatomists overcame these difficulties and created detailed medical drawings of the lymphatic system based on their dissections. These drawings continue to be a feature of current anatomical textbooks.

In this article, we provide an overview of the historical techniques used in the study of lymphatic anatomy and introduce our own contribution to this field.

\section{HISTORICAL REVIEWS}

\section{Dissection of living animals - discovery of the lymphatic system}

Discovery of the lymphatic system is credited to the Italian anatomist Aselli ${ }^{[10]}$ [Figure 1]. When Aselli was asked by his colleague to demonstrate the recurrent nerve in a living dog, he noticed by chance that 

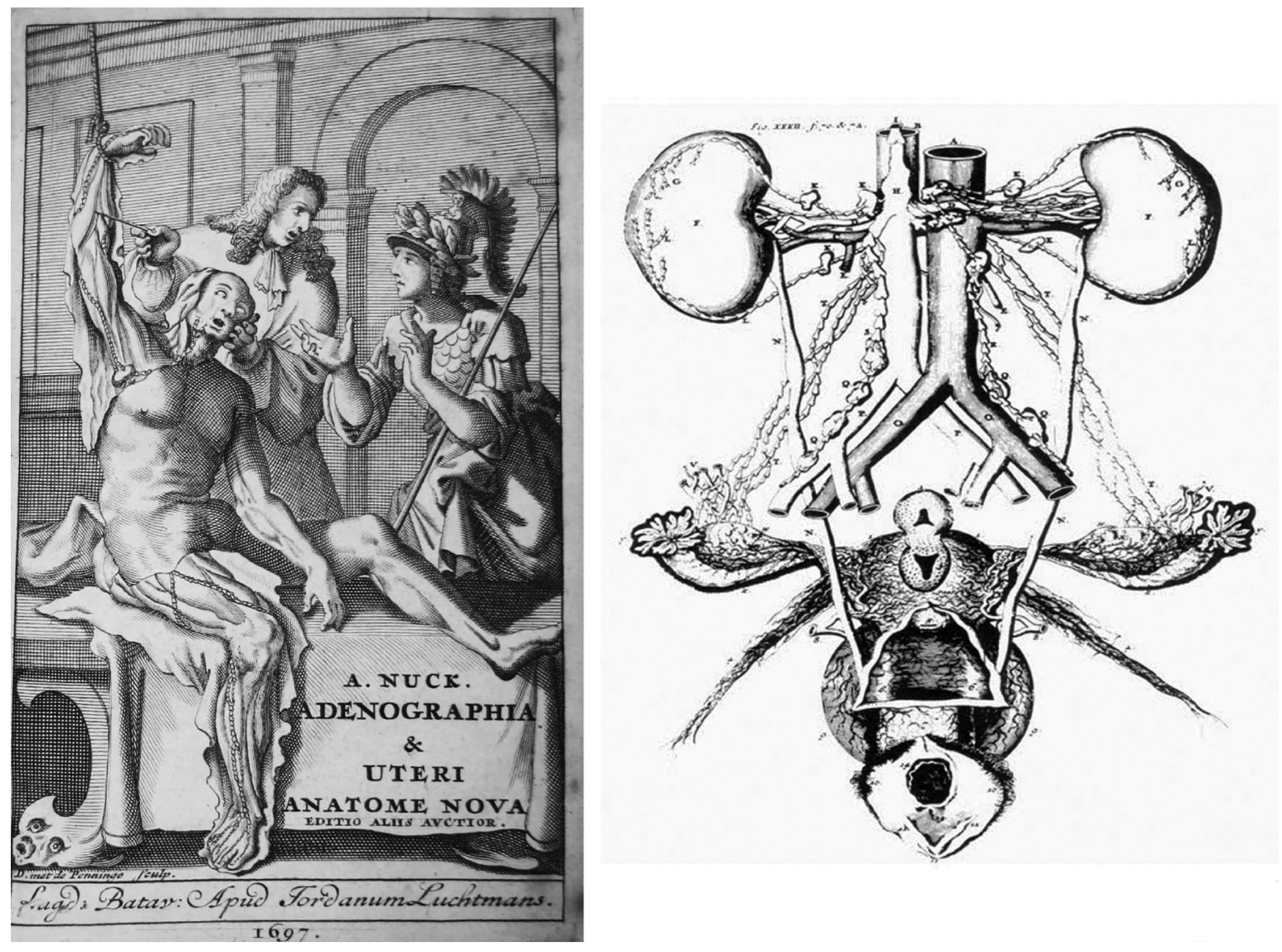

Figure 2. Nuck's ${ }^{[13]}$ publication in 1696. Mercury injection was applied to the lymphatic vessels in the female reproductive organs (right)

there were many white cords running in the mesentery. Initially, he thought that these cords were nerves, but when he cut them with scissors, he observed milky liquid (lacteal) gushing from the vessels. Aselli attempted to reproduce his findings on another day, but could not find the same type of structure. He then realised that these structures correlated with the absorption of nutrients from the small intestine, because being able to see the vessels depended on the timing of feeding ${ }^{[11]}$.

Aselli's findings were magnificent and shed light on a new body system. However, the dissection of living animals had limitations for further investigation and led him to the misconception that these vessels connected to the liver, rather than the thoracic duct.

\section{Mercury injection}

Malpighi used mercury to observe the arterioles, because he knew mercury was a slippery agent that could penetrate into smaller vessels ${ }^{[12]}$. Nuck ${ }^{[13]}$ made an amalgam by mixing mercury with tin and lead. He used this mixture to identify the lymphatics and his illustrations of the lymphatic vessels are very well detailed [Figure 2] ${ }^{[13]}$. Mercury injection became the standard technique for anatomical investigation of the lymphatic system for the next three centuries ${ }^{[14]}$.

Mascagni ${ }^{[15]}$ was one of the anatomists who used mercury injection and published his extensive studies in $1787^{[16]}$. His contribution to the field is not only his book containing detailed anatomical illustrations, but also the life-size wax models he created. Mascagni supervised modellers Felice Fontana and Clemente Susini in creating wax models for anatomical teaching ${ }^{[17,18]}$. These masterpiece models are well preserved and are still on display at the La Specola Museum in Florence and Josephinum Museum in Vienna. 


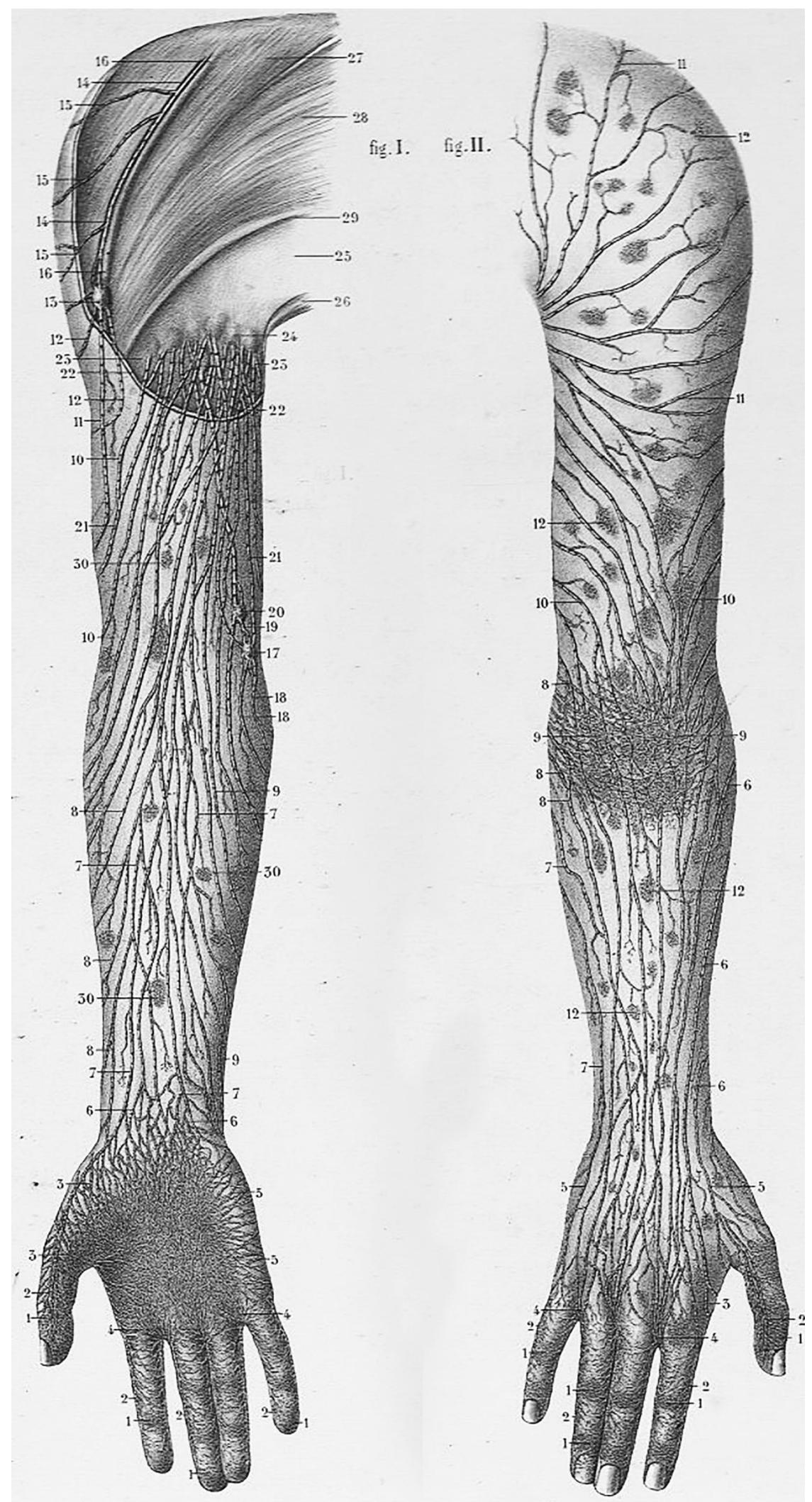

Figure 3. Illustration from Sappey's ${ }^{[19]}$ book showing lymphatic vessels in the upper extremity identified using the mercury injection technique 

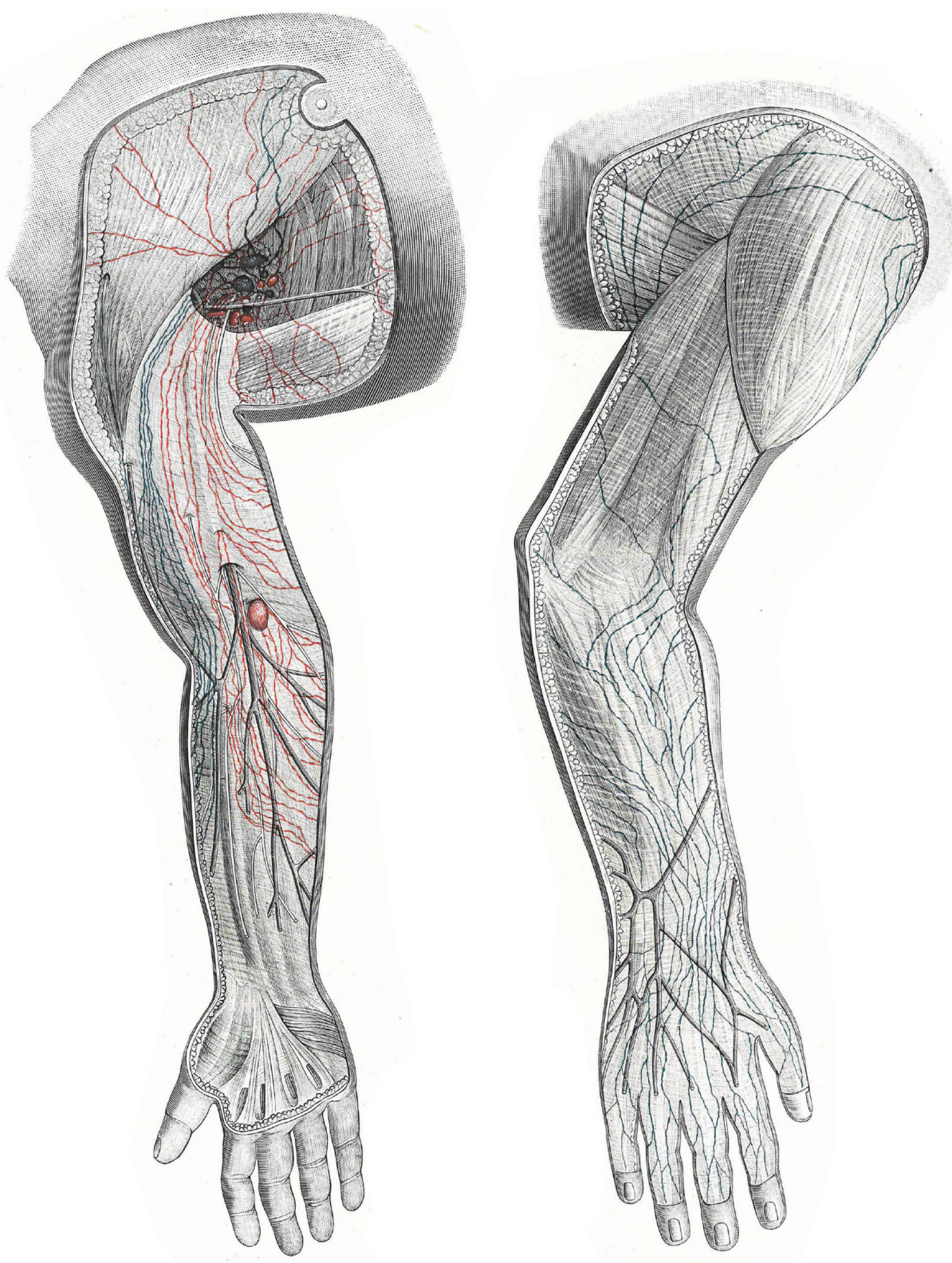

Figure 4. Illustration from Bartels ${ }^{\prime 24]}$ book showing lymphatic vessels in the upper extremity identified using Gerota's method

Sappey ${ }^{[19]}$ also used the mercury injection technique and published his findings in 1874 [Figure 3]. His book provided a comprehensive understanding of the human lymphatics, but his superb illustrations were more of artistic than scientific value. Sappey was probably the first anatomist to understand the idea of lymphatic territories defined by a watershed at the midline and a horizontal line crossing the umbilicus in the torso.

To date, anatomical findings with mercury injection were the mainstay of our understanding of the lymphatic system. Anatomists injected mercury directly into the lymphatic vessels or indirectly into the skin in cadaveric specimens using stretched glass tubes or fine needles. The excellent illustrations made by the early anatomists led to the belief that mercury was an ideal material for demonstrating the lymphatics, but it has several downsides. Firstly, mercury is a toxic substance and its use in anatomical investigation was discontinued in the early twentieth century due to concerns about health issues. Secondly, mercury 

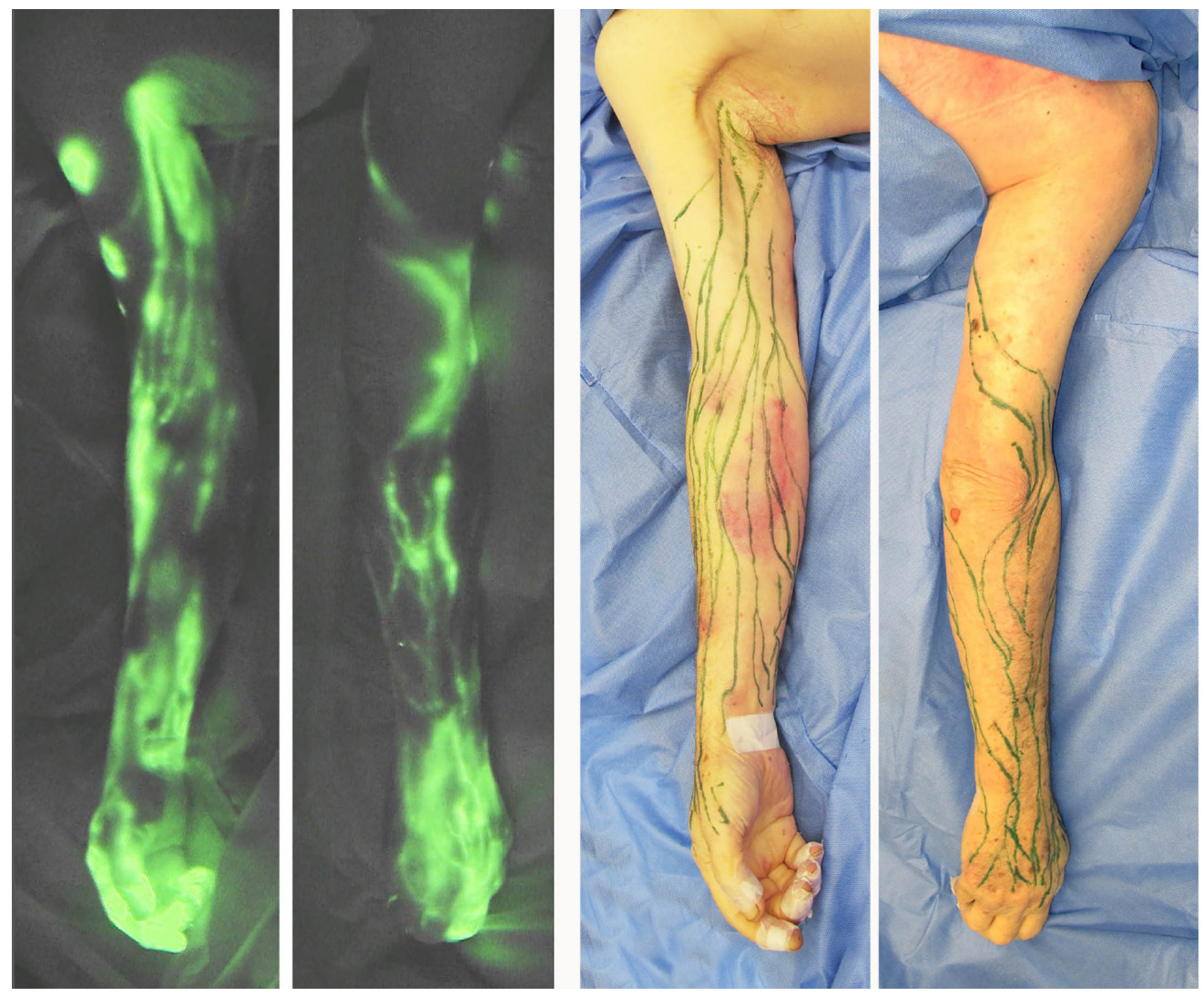

Figure 5. Indocyanine green lymphography image in the upper extremity in a fresh cadaver (left). Lymphatic mapping in the same specimen (right)

was an imperfect tool for identifying the lymphatics. A young male cadaver that had been studied using a mercury injection in the 18th century, possibly by Alexander Monro the Second (1733-1817), was stored at the University of Edinburgh ${ }^{[20]}$. When this cadaver was later submitted to radiographic investigation, the radiographs revealed that the mercury had entered not only the lymphatic vessels, but also the veins $^{[21]}$. This finding suggests that the anatomists doing the illustrations must have spent a lot of time and effort in manually extracting the information about the lymphatics to create their drawings. Finally, the mercury injection technique was limited in the number of lymphatic vessels that could be identified in each specimen. Hence, Sappey needed to combine findings from multiple specimens to compose a single diagram.

Despite these several downsides of the technique, the painstaking efforts made by pioneer anatomists who used mercury injection succeeded in establishing the solid foundation of lymphatic anatomy for three centuries, and our current knowledge still relies heavily on their achievement.

\section{Dye injection}

As a potential replacement for mercury injection, a dye injection method for demonstrating the lymphatics was developed by Gerota ${ }^{[22]}$ in a technique known as Gerota's method. Gerota's original medium was composed of Prussian blue diluted with turpentine and ether and his method was used by Rouvière ${ }^{[23]}$ and Bartels $^{[24]}$ and contributed to their publications [Figure 4].

While studies using mercury injection used mainly adult cadaver specimens, Gerota's method required the use of foetal and child cadavers. The reason for this is that the slippery nature of mercury allowed 

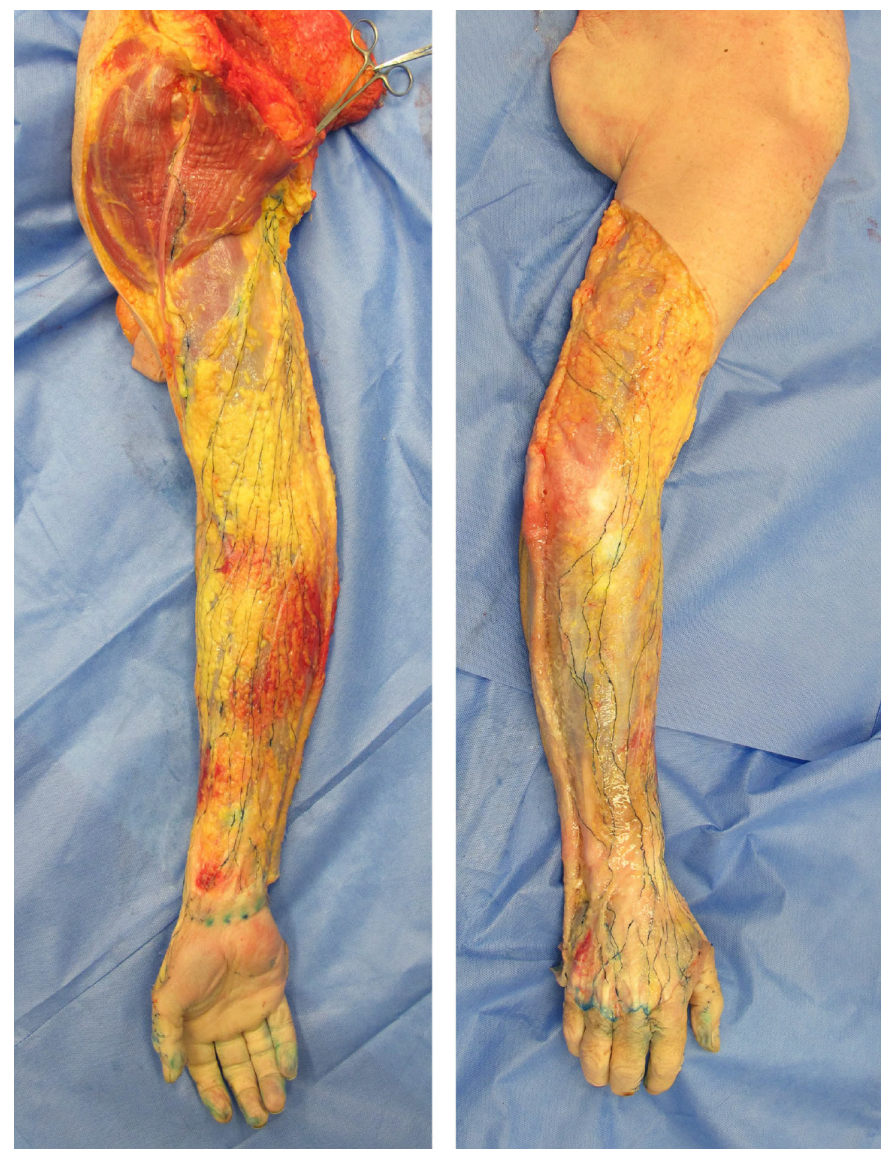

Figure 6. Lymphatic vessels in the specimen in Figure 5 shown using the microinjection technique

it to travel long distances inside the lymphatic vessels, but the dye used in Gerota's method could only travel much shorter distances. To overcome this limitation, anatomists began using smaller bodies, but the difficulty of acquiring a steady supply of foetal specimens became a barrier to anatomical study and was the major factor in the decline of lymphatic anatomy research in the twentieth century. Foetal studies using Gerota's method still continue at the Department of Anatomy at the University of Buenos Aires, where the method is combined with the Spalteholz technique to render tissues translucent ${ }^{[25]}$.

\section{Microinjection technique with hydrogen peroxide}

A new technique to investigate the lymphatic system in adult cadaver specimens without using mercury was developed by Suami et al. ${ }^{[26,27]}$. In contrast to arteries and veins that contain red blood cells, transparent lymphatic vessels cannot be identified with the naked eye post-mortem because they collapse. Initially, patent blue violet was injected into the cadaver to identify the lymphatic vessels. The dye succeeded in demonstrating some lymphatic vessels, but it also stained the surrounding tissue and prevented any further investigation. After this, hydrogen peroxide was used and found to be an ideal substance to distinguish the lymphatic vessels from the surrounding soft tissue without any contamination. When hydrogen peroxide is injected into the skin and subcutaneous tissue around the area of investigation, its reaction with tissue enzymes produces fine bubbles of oxygen. These bubbles inflate the lymphatic vessels so they can be identified under a surgical microscope. When the location of the vessels has been determined, a fine stretched glass tube or needle is directly cannulated into them and a contrast agent (a radiocontrast medium or dye) is injected to stain them with colour. Once coloured, the vessels can easily be dissected out from the soft tissue. The whole procedure is performed under a surgical microscope and therefore has become known as the microinjection technique. Compared to both the mercury injection technique and 
Gerota's method, the microinjection technique requires more dextrous skills in manipulating lymphatic vessels under the microscope.

When a radiocontrast medium is selected as the contrast agent, the prospective radiographic images are similar to those produced by lymphoangiography in live subjects. Lymphangiography is an invasive procedure requiring a small surgery consisting of cutting the skin and cannulating a fine needle into a lymphatic vessel under local anaesthesia ${ }^{[1]}$. Usually, only one lymphatic vessel is cannulated. In contrast to lymphoangiography, the microinjection technique in cadaver specimens has no limitation on the number of lymphatic vessels that can be identified, so has the advantage of allowing the researcher to obtain a comprehensive picture of the lymphatics in each specimen. The disadvantage of the microinjection technique is that the contrast medium stops at the sentinel node, so further cannulation in the efferent vessel of the node is essential if the proximal areas are to be investigated. However, the invention of the microinjection technique enabled anatomists to undertake the study of lymphatic anatomy in adult cadavers and contributed to better lymphatic mapping of the body regions ${ }^{[28-31]}$.

\section{Indocyanine greenlymphography}

ICG lymphography was initially developed to map the sentinel lymph nodes for breast cancer treatment ${ }^{[32]}$. Its application was then expanded to provide imaging for the diagnosis of lymphoedema ${ }^{[4-6]}$. ICG is a watersoluble agent that emits near infrared-rays when it combines with protein in the human body. When ICG is injected into the skin, it automatically enters the lymphatic vessels. The infrared camera then scans the limb and captures the emitted signals, causing the vessels to glow green so that they can be identified in real time to a depth of $2 \mathrm{~cm}$ from the surface of the skin.

The authors injected ICG into fresh cadavers and confirmed that it was able to identify the lymphatic vessels in post-mortem specimens ${ }^{[3,34]}$. ICG lymphography was found to be consistent in identifying the lymphatics and the dye was able to travel long distances from the injection site if fresh, non-frozen cadavers were used. The technique has demonstrated several advantages in anatomical study in a cadaver model. Firstly, lymphatic vessels can be identified without a skin incision, so ICG injections do not disrupt the embalming process to follow and the bodies can be reutilised for anatomical dissection after study of the lymphatics. Secondly, ICG mapping has helped make the microinjection technique more effective, as it provides a more efficient way of locating the lymphatic vessels than injecting hydrogen peroxide, the most time-consuming part of the process. Finally, it has enabled fast mapping of the course of lymphatic vessels and allowed the capture of imaging data from multiple cadaver specimens ${ }^{[35]}$.

\section{AUTHOR'S CURRENT METHOD}

Finally, this paper briefly introduces the specific method we currently use for anatomical investigation of the lymphatic system in a cadaver model. Cadaver specimens are obtained from the institutional willed body program with appropriate approval for their use in scientific investigation. Fresh, non-embalmed and non-frozen specimens are ideal, but previously frozen and thawed specimens can also be used. ICG (Verdye $25 \mathrm{mg}$, Diagnostic Green GmbH, Germany) is mixed with $20 \mathrm{~mL}$ of saline. Taking the investigation in an upper extremity as an example, $0.1 \mathrm{~mL}$ doses of ICG solution are injected intradermally into the sides of fingers and several spots in the anterior wrist. After a few minutes of massage at the injection sites, the ICG dye starts entering the lymphatic vessels. Inside the lymphatic vessel, the dye is moved from the distal to proximal by massaging the skin in an axial direction. If the specimen is within a few days post-mortem, the ICG moves all way to the axillary nodes and the course of the vessels is demonstrated with the infrared camera (Photodynamic Eye Neo II, Hamamatsu K.K., Japan). A marker pen is used to mark the lymphatic vessels on the surface of the skin [Figure 5].

If the specimens are needed for further dissection and for use in an anatomical teaching workshop, the microinjection technique is then applied ${ }^{[33]}$. Five per cent hydrogen peroxide with/without dye is injected 

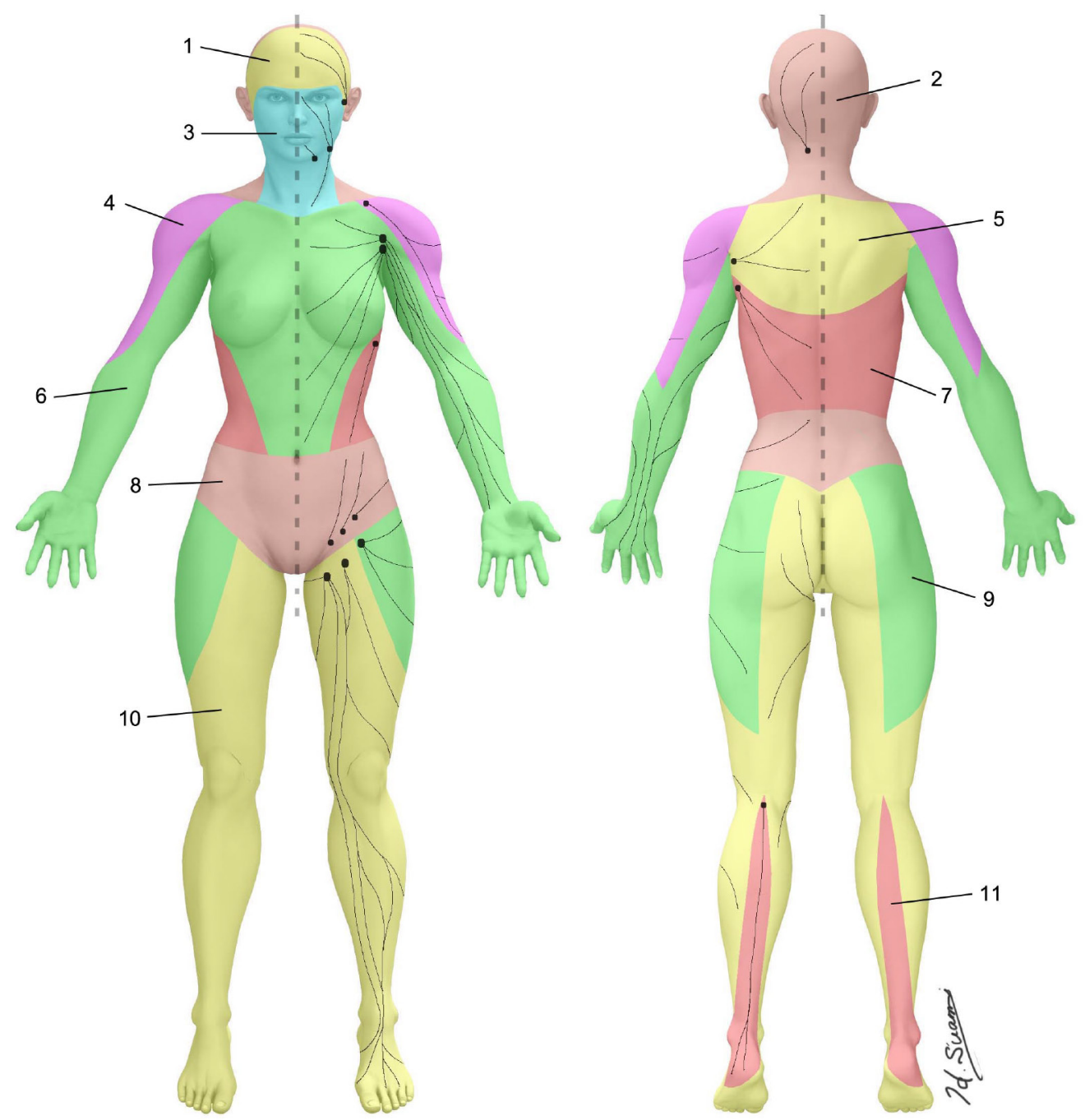

Figure 7. Lymphosomes of the body. The lymphatic territories are demarcated according to their corresponding lymphatic basins: (1) temporal; (2) occipital; (3) submental; (4) subclavicular; (5) subscapular; (6) lateral axillary; (7) pectoral; (8) superior inguinal; (9) lateral inguinal; (10) inferior inguinal; and (11) popliteal. (Reproduced with permission of Suami ${ }^{[37]}, 2018$ )

around the lymphatic vessels identified by the ICG mapping to inflate them for cannulation. The inflated vessels are easily identified in the subcutaneous tissue below the area that has been marked. A $30 \mathrm{G}$ needle connected to an extension tube and $1 \mathrm{~mL}$ syringe is set with a micromanipulator (UMM-3FC and UM-1PFC, Narishige Group Co., Japan) and cannulated into the lymphatic vessel. A coloured substance with/without a radiocontrast medium is injected into the lymphatic vessels by manually pumping the $1 \mathrm{~mL}$ syringe. After removing the skin just above the stained lymphatic vessels, the lymphatic course is traced until the vessels reach their corresponding lymph nodes [Figure 6].

The combination of ICG lymphography and the microinjection technique works effectively in fresh adult cadavers. We applied this technique to map the lymphatics and found that the skin can be demarcated into groups of lymphatic vessels that connect to the same regional nodes. The author coined the word "lymphosome" to describe these separate lymphatic territories [Figure 7$]^{[36,37]}$.

Significant anatomical changes occur in lymphoedema ${ }^{[38-40]}$. Understanding the normal anatomy of the lymphatics is essential to allow doctors and researchers to distinguish how lymphatic structures altered by lymphoedema differ from the original condition. New imaging techniques continue to be developed and 
provide new types of lymphatic images. Physicians need to be able to interpret these images accurately to specify the pathology of lymphatic dysfunction, and anatomical study of the lymphatics is essential to provide the required baseline information.

\section{CONCLUSION}

This paper focuses on the techniques that have enabled anatomists to investigate the lymphatic system in cadavers over the past several hundred years. Mercury injection was the mainstay of lymphatic study for many years and our current knowledge still largely depends on findings from more than 100 years ago. New imaging techniques are being developed in the clinical setting, and anatomical research needs to be updated to incorporate these new techniques to provide further information about the lymphatic system.

\section{DECLARATIONS}

\section{Acknowledgments}

The authors thank Philippa Sutton for editorial assistance with the preparation of this article.

\section{Authors' contributions}

Study concept and data acquisition: Suami H

Data interpretation and manuscript drafting: Suami H, Shinaoka A

\section{Availability of data and materials}

Not applicable.

\section{Financial support and sponsorship}

None.

\section{Conflicts of interest}

All authors declared that there are no conflicts of interest.

\section{Ethical approval and consent to participate}

Not applicable.

\section{Consent for publication}

Not applicable.

\section{Copyright}

(c) The Author(s) 2019.

\section{REFERENCES}

1. Kinmonth JB. Lymphangiography in man; a method of outlining lymphatic trunks at operation. Clin Sci 1952;11:13-20.

2. Weissleder H, Weissleder R. Lymphedema: evaluation of qualitative and quantitative lymphoscintigraphy in 238 patients. Radiology 1988;167:729-35.

3. Golueke PJ, Montgomery RA, Petronis JD, Minken SL, Perler BA, et al. Lymphoscintigraphy to confirm the clinical diagnosis of lymphedema. J Vasc Surg 1989;10:306-12.

4. Ogata F, Narushima M, Mihara M, Azuma R, Morimoto Y, et al. Intraoperative lymphography using indocyanine green dye for nearinfrared fluorescence labeling in lymphedema. Ann Plast Surg 2007;59:180-4.

5. Unno N, Inuzuka K, Suzuki M, Yamamoto N, Sagara D, et al. Preliminary experience with a novel fluorescence lymphography using indocyanine green in patients with secondary lymphedema. J Vasc Surg 2007;45:1016-21.

6. Suami H, Chang DW, Yamada K, Kimata Y. Use of indocyanine green fluorescent lymphography for evaluating dynamic lymphatic status. Plast Reconstr Surg 2011;127:74e-6e.

7. Liu NF, Yan ZX, Wu XF, Luo Y. Magnetic resonance lymphography demonstrates spontaneous lymphatic disruption and regeneration in obstructive lymphedema. Lymphology 2013;46:56-63. 
8. Arrive L, Derhy S, Dlimi C, El Mouhadi S, Monnier-Cholley L, et al. Noncontrast magnetic resonance lymphography for evaluation of lymph node transfer for secondary upper limb lymphedema. Plast Reconstr Surg 2017;140:806e-11e.

9. Baulieu F, Bourgeois P, Maruani A, Belgrado JP, Tauveron V, et al. Contributions of SPECT/CT imaging to the lymphoscintigraphic investigations of the lower limb lymphedema. Lymphology 2013;46:106-19.

10. Aselli G. De lactibus, sive lacteis venis, quarto vasorum mesaraicorum genere novo inuento. Milan, Italy; 1627.

11. Leeds SE. Three centuries of history of the lymphatic system. Surg Gyenecol Obstet 1977; 144:927-934.

12. Young J. Malpighi's “De Pulmonibus”. Proc R Soc Med 1929;23:1-11.

13. Nuck A. Adenographia curiosa et uteri foeminei anatome nova. Lugduni Betavorum, P. vander Aa; 1692.

14. Handriksen MM. Anatomical mercury: changing understandings of quicksilver, blood, and the lymphatic system, 1650-1800. J Hist Med Allied Sci 2015;70:516-48.

15. Mascagni P. Vasorum lymphaticorum corporis humani historia et ichnographia. Sienna: P Carli; 1787.

16. Bertelli R. Paolo Mascagni (1755-1815). J Cardiovasc Surg (Torino) 1961;2:414-21.

17. Riva A, Conti G, Solinas P, Loy F. The evolution of anatomical illustration and wax modelling in Italy from the 16 th to early 19 th centuries. J Anat 2010;216:209-22.

18. Hilloowala R, Renahan J. 18th-Century anatomical models at La-Specola, Florence. Anat Anzeiger 1985;159:141-58.

19. Sappey MPC. Amatomie, physiologie, pathologie des vesseaux lymphatiques consideres chez l'homme et les vertebres. Paris A 1885 .

20. Kaufman MH. Observations on some of the plates used to illustrate the lymphatics section of Andrew Fyfe's compendium of the anatomy of the human body, published in 1800. Clin Anat 1999;12:27-34.

21. Kaufman MH, Best JJ. Monro Secundus and 18th century lymphangiography. Proc R Coll Physicians Edinb 1996;26:75-90.

22. Gerota D. Zur technik der lymphgefassinjection. Eine neue injectionmasse fur lymphgefasse. Polychrom injection. Anat Anz 1896;12:216-24.

23. Rouvière H. Anatomie des lymphatiques de l'Homme. Paris; 1981.

24. Bartels P. Das lymphgefässsystem. In: BARDELEBEN, Handbuch der Anatomie des Menschen. Jena: Gustav Fischer; 1909.

25. Amore M, Tapia L, Mercado D, Pattarone G, Ciucci J. Lymphedema: a general outline of its anatomical base. J Reconstr Microsurg 2016;32:2-9.

26. Suami H, Taylor GI, O’Neill J, Pan WR. Refinements of the radiographic cadaver injection technique for investigating minute lymphatic vessels. Plast Reconstr Surg 2007;120:61-7.

27. Suami H, Taylor GI, Pan WR. A new radiographic cadaver injection technique for investigating the lymphatic system. Plast Reconstr Surg 2005;115:2007-13.

28. Suami H, Taylor GI, Pan WR. The lymphatic territories of the upper limb: anatomical study and clinical implications. Plast Reconstr Surg 2007;119:1813-22.

29. Pan WR, Suami H, Taylor GI. Lymphatic drainage of the superficial tissues of the head and neck: anatomical study and clinical implications. Plast Reconstr Surg 2008;121:1614-24; discussion 25-6.

30. Suami H, O’Neill JK, Pan WR, Taylor GI. Superficial lymphatic system of the upper torso: preliminary radiographic results in human cadavers. Plast Reconstr Surg 2008;121:1231-9.

31. Suami H, Pan WR, Mann GB, Taylor GI. The lymphatic anatomy of the breast and its implications for sentinel lymph node biopsy: a human cadaver study. Ann Surg Oncol 2008;15:863-71.

32. Kitai T, Inomoto T, Miwa M, Shikayama T. Fluorescence navigation with indocyanine green for detecting sentinel lymph nodes in breast cancer. Breast Cancer 2005;12:211-215.

33. Scaglioni MF, Suami H. Lymphatic anatomy of the inguinal region in aid of vascularized lymph node flap harvesting. J Plast Reconstr Aesthet Surg 2015;68:419-27.

34. Shinaoka A, Koshimune S, Yamada K, Kumagishi K, Suami H, et al. A fresh cadaver study on indocyanine green fluorescence lymphography: a new whole-body imaging technique for investigating the superficial lymphatics. Plast Reconstr Surg 2018;141:1161-4.

35. Shinaoka A, Koshimune S, Yamada K, Kumagishi K, Suami H, et al. Correlations between tracer injection sites and lymphatic pathways in the leg: a near-infrared fluorescence lymphography study. Plast Reconstr Surg 2019;144:634-42.

36. Suami H. Lymphosome concept: anatomical study of the lymphatic system. J Surg Oncol 2017;115:13-7.

37. Suami H, Scaglioni MF. Anatomy of the lymphatic system and the lymphosome concept with reference to lymphedema. Semin Plast Surg 2018;32:5-11.

38. Suami H, Pan WR, Taylor GI. Changes in the lymph structure of the upper limb after axillary dissection: radiographic and anatomical study in a human cadaver. Plast Reconstr Surg 2007;120:982-91.

39. Suami H, Koelmeyer L, Mackie H, Boyages J. Patterns of lymphatic drainage after axillary node dissection impact arm lymphoedema severity: a review of animal and clinical imaging studies. Surg Oncol 2018;27:743-50.

40. Suami H, Heydon-White A, Mackie H, Czerniec S, Koelmeyer L, et al. A new indocyanine green fluorescence lymphography protocol for identification of the lymphatic drainage pathway for patients with breast cancer-related lymphoedema. BMC Cancer 2019;19:985. 